\title{
Aplikasi Smartphone Efektif digunakan untuk Pengawasan Keseimbangan Cairan pada Anak dengan Penyakit Infeksi
}

\author{
Smartphone Applications are Effective in Monitoring Fluid Balance in Pediatric With \\ Infectious Desease
}

\author{
Nuraidah $^{1,2}$, Nani Nurhaeni ${ }^{1}$, Dessie Wanda ${ }^{1}$ \\ 'Departemen Keperawatan Anak Fakultas IImu Keperawatan Universitas Indonesia, Depok, \\ Jawa Barat, Indonesia
}

${ }^{2}$ RSPI Prof. Dr. Sulianti Saroso, Jakarta

*Korespondensi Penulis :

Nuraidah dan Email: nuraidah.ai@gmail.com

\begin{abstract}
Abstrak
Latar belakang: Keseimbangan cairan sangat penting untuk kelangsungan hidup sehingga pengawasan cairan perlu diperhatikan. Pencatatan keseimbangan cairan diperlukan untuk menjadi dasar penilaian yang akurat dari status keseimbangan cairan pasien anak dan menjadi dasar pertimbangan pemberian terapi selanjutnya. Untuk memudahkan perawat melakukan pencatatan keseimbangan cairan yang akurat diperlukan inovasi menggunakan teknologi berbasis smartphone. Penelitian ini bertujuan untuk mengetahui perbedaan efektifitas pengawasan cairan menggunakan lembar observasi dengan aplikasi smartphone. Metode: Penelitian ini diawali dengan pengembangan aplikasi smartphone bernama SIMBaCaAn berdasarkan tinjauan pustaka yang dilakukan menggunakan pendekatan PICO (Population, Intervention, Comparison,Outcome). Uji efektifitas aplikasi SIMBaCaAn dilakukan pada 48 pasien anak yang dirawat di salah satu rumah sakit rujukan di DKI Jakarta. Analisis data dilakukan menggunakan uji statistik Kappa Test. Hasil: Pengawasan keseimbangan cairan yang menggunakan lembar observasi menghasilkan pencatatan data tidak lengkap sebesar $14,6 \%$, data lengkap tidak tepat $20,8 \%$ dan data lengkap tepat sebanyak 64,4 $\%$. Sedangkan pengawasan keseimbangan cairan menggunakan aplikasi SIMBaCaAn didapatkan hasil data tidak lengkap 18,7\% dan hasil data lengkap tepat 81,3\%. Dari hasil uji statistik, ditemukan perbedaan yang signifikan antara pengawasan keseimbangan cairan menggunakan aplikasi dan lembar observasi. Kesimpulan: Aplikasi smartphone lebih efektif terhadap pencatatan keseimbangan cairan secara lengkap tepat dibandingkan dengan lembar observasi manual.
\end{abstract}

Kata kunci: Aplikasi, Pengawasan Cairan, Anak, Smartphone

\begin{abstract}
Introduction: Fluid balance is very important for survival so fluid monitoring needs to be considered. Recording fluid balance is needed to be the basis for an accurate assessment of the fluid balance status of pediatric patients and the basis for consideration of further therapy. To make it easier for nurses to record accurate fluid balance, innovation using smartphone-based technology is needed. This innovation project aims to determine the difference in the effectiveness of liquid monitoring using an observation sheet with a smartphone application. Methods: This innovation project was initiated by developing a smartphone application named SIMBaCaAn following a literature review using the PICO approach (Population, Intervention, Comparison, Outcome). This application was tested for its effectiveness involving 48 pediatric patients in one top referral hospital in DKI Jakarta. The data was analyzed using Kappa test. Result: Data show that in monitoring fluid balance using observation sheets, $64.4 \%$ data was accurate and complete, $20.8 \%$ inaccurate but complete, and $14.6 \%$ was incomplete data. While, in monitoring fluid balance using the SIMBaCaAn application, $81.3 \%$ was accurate and complete, and the rest $18.7 \%$ was incomplete but accurate. Conclusion: Smartphone applications are more effective at recording complete fluid balance accurately compared to manual observation sheets.
\end{abstract}

Keywords: Application, Fluid Monitoring, Children, Smartphone 


\section{Pendahuluan}

Berdasarkan data ruangan di salah satu ruang infeksi salah satu rumah sakit negeri di Jakarta pada triwulan I tahun 2021 didapatkan data 83\% catatan lembar monitoring cairan yang terisi secara lengkap, tetapi belum dilakukan audit ketepatannya. Hampir seluruh pasien anak yang dirawat mendapatkan terapi cairan intravena sehingga monitoring cairan yang tepat sangat diperlukan.

Air merupakan komponen penting dalam tubuh anak. Total cairan tubuh anak berkisar antara 65 - $70 \%$ sehingga apabila terjadi kekurangan cairan akan menyebabkan masalah serius pada anak. ${ }^{1} \quad$ Keseimbangan cairan mempengaruhi kelangsungan hidup dan homeostasis organisme karena itu konsentrasi cairan dan elektrolit perlu dipertahankan agar semua sel berfungsi norma. ${ }^{2}$ Keseimbangan cairan dalam tubuh diatur oleh sistem neuroendokrin dan dapat berubah pada saat tubuh mengalami sakit. ${ }^{3,4}$

Pengawasan keseimbangan cairan harus jelas dan terukur agar keakuratan pengukuran dan ketepatan pencatatan tercapai. Alat ukur seperti gelas ukur dan timbangan popok sekali pakai harus selalu tersedia di ruang perawatan anak untuk mendukung ketepatan pengukuran. Apabila pasien mendapatkan terapi cairan intravena maka sebelum dilakukan terapi cairan dan selama mendapat terapi cairan, pasien anak harus ditimbang secara reguler. Hal ini dilakukan untuk menjaga keakuratan saat dilakukan pengawasan cairan. $^{5}$

Pencatatan keseimbangan cairan diperlukan untuk menjadi dasar penilaian yang akurat dari status keseimbangan cairan pasien dan menjadi dasar pertimbangan pemberian terapi selanjutnya. Selain itu data keseimbangan cairan yang tepat dapat membantu deteksi dini gangguan pada organ tubuh. ${ }^{6}$ Pengawasan keseimbangan cairan merupakan tugas mandiri perawat yang harus dilakukan secara berkesinambungan pada setiap shift. ${ }^{7}$ Untuk mendapatkan data intake output yang akurat perlu kerjasama yang baik antara perawat dengan orang tua. Dalam hal ini tugas orang tua adalah mengingat dan menuliskan intake output anak yang sakit di kertas catatan pribadi pasien atau pun di telepon selulernya. Selanjutnya, perawat akan memindahkan hasil catatan tersebut dalam lembar observasi catatan keperawatan dan menghitung keseimbangan cairan anak.

Kondisi di salah satu ruang perawatan anak di salah satu rumah sakit rujukan di DKI Jakarta menggambarkan pencatatan pengawasan keseimbangan cairan 
belum berjalan optimal. Berdasarkan hasil wawancara dengan kepala ruangan tabel pencatatan intake output yang sudah ada untuk diisi orangtua terkendala biaya dalam proses penggandaan sehingga ketersediaan lembar pencatatan menjadi terhambat dan orang tua menulis pada kertas atau buku masing masing. Hambatan lainnya adalah pemahaman orang tua atau pendamping anak dalam menghitung intake output belum sama, sehingga perlu dilakukan edukasi awal bagaimana cara pengukuran masukan dan keluaran dan cara mencatatnya.Untuk mempermudah pencatatan dan penghitungan keseimbangan cairan, aplikasi yang berbasis smartphone telah digunakan di negara lain seperti salah satu rumah sakit yang ada di United Kingdom (UK), Thailand..$^{7,8}$ Berdasarkan hal tersebut penulis tertarik untuk melakukan inovasi pengembangan aplikasi berbasis smartphone. Tujuan dari penelitian ini adalah untuk mengetahui perbedaan efektifitas pengawasan cairan menggunakan lembar observasi dengan aplikasi smartphone.

\section{Metode}

Penelitian ini merupakan kegiatan pengembangan aplikasi berbasis smartphone yang digunakan sebagai alat bantuk dalam pemantauan keseimbangan cairan pasien anak. Aplikasi ini dikembangkan diawali dengan tinjauan pustaka yang dilakukan menggunakan pendekatan PICO (Population $=$ pasien anak; Intervention = pencatatan menggunakan aplikasi berbasis smartphone; Comparison = pencatatan secara manual; Outcome $=$ ketepatan dan kelengkapan pencatatan). Aplikasi yang dikembangkan diberi nama Sistem Informasi Balans Cairan Anak (SIM BaCaAn). Penelitian ini telah mendapat ethical clearance dari komite etik RSPI Prof Dr Sulianti Saroso dengan nomor izin etik 19/XXXVIII.10/VII/2021.

Proses pelaksanaan penelitian ini terdiri dari tiga tahap. Tahap pertama adalah melakukan sosialisasi alamat website dan cara pengisian aplikasi SIMBaCaAn kepada perawat dan memasukan data perawat agar bisa login pada aplikasi. Pada tahap ini dilakukan penyamaaan persepsi tentang pengisian jenis intake dan output yang di masukan ke dalam aplikasi dan dilakukan uji coba pada pasien yang ada. Waktu sosialisasi dilakukan selama satu minggu. Selanjutnya, tahap kedua dilakukan uji coba kepada pendamping pasien. Tahap ini diawali dengan memberikan pemahaman kepada pendamping tentang apa yang masuk dalam kategori 
intake dan output dan bagaimana cara pengukurannya yang tepat sebelum menuliskan ke catatan kertas dan memasukan data ke aplikasi SIMBaCaAn. Tahap ketiga adalah ujicoba efektivitas aplikasi SIMBaCaAn. Ujicoba ini melibat 48 pasien anak. Kriteria inklusi yang digunakan untuk memilih pasien anak yang terlibat adalah anak yang dirawat di ruang infeksi, orang tua atau pendamping memiliki smartphone, orangtua mengizinkan anak terlibat dalam penelitian. Sedangkan kriteria eksklusi adalah pasien anak yang dirawat di ruang infeksi kurang dari 24 jam dikarenakan pindah ruangan, meninggal atau pulang, atau pengasuh yang tidak memiliki smartphone. Prosedur yang dilakukan untuk tiap pasien anak adalah di hari pertama orangtua melakukan pencatatan intake dan output cairan secara manual seperti yang selama ini dilakukan di ruang rawat. Selanjutnya di hari kedua, orang tua akan melakukan pencatatan menggunakan aplikasi SIMBaCaAn. Tahap ujicoba efektivitas ini dilakukan selama satu minggu.

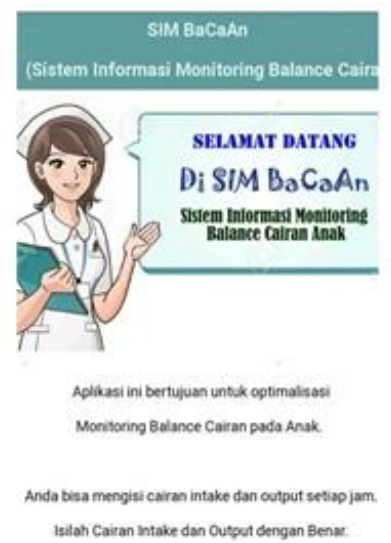

A

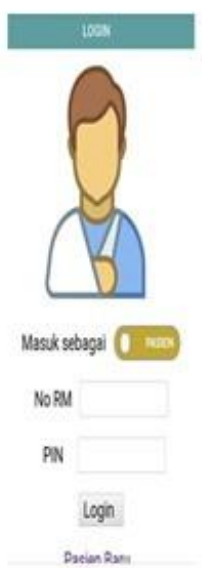

B

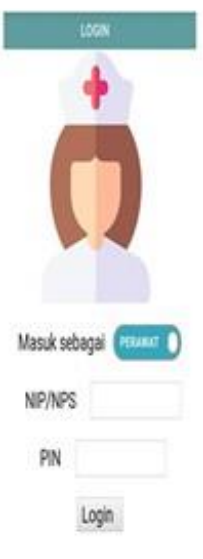

C
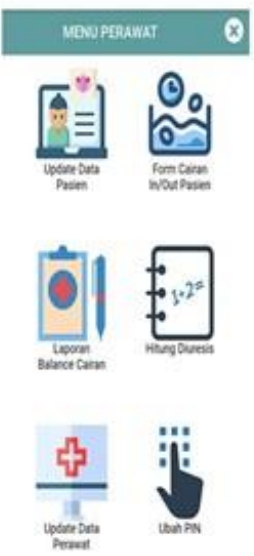

D

Gambar A. Tampilan Awal, B. Login Pasien, C. Login Perawat, D. Menu Utama

Gambar 1. Tampilan fitur pada aplikasi yang dikembangkan 
Kriteria hasil yang digunakan untuk mengevaluasi pencatatan intake dan output adalah ketepatan dan kelengkapan informasi. Data dianggap tidak lengkap bila teridentifikasi ketidaksesuaian data yang dicatat oleh orang tua secara manual di kertas dan aplikasi SIMBaCaAn dibandingkan dengan data yang dicatat oleh residen. Kategori kedua adalah data lengkap tidak tepat apabila data yang dicatat lengkap namun terjadi kesalahan dalam menghitung jumlah total intake output atau perawat tidak menghitung Insensible Water Loss (IWL), karena hal ini berdampak pada ketidaktepatan penghitungan balans cairan. Kategori ketiga adalah data lengkap tepat apabila data intake dan output ditulis lengkap dan penghitungan yang dilakukan juga tepat. Analisa data yang digunakan adalah uji Kappa.

\section{Hasil}

Anak yang menjadi responden terbanyak adalah kelompok infant $(43,8 \%)$. Sementara kelompok yang paling sedikit adalah kelompok preschool (8,3\%). Sementara kelompok yang paling sedikit adalah kelompok preschool (8,3\%). Anak laki laki lebih banyak yang dirawat yaitu $66,7 \%$, sementara anak perempuan 33,3\% (Tabel 1).
Tabel 1. Karakteristik anak yang dirawat di ruang infeksi Mei-Juni 2021 ( $n=48)$

\begin{tabular}{|c|c|c|}
\hline Variabel & $\mathbf{n}$ & Persen \\
\hline \multicolumn{3}{|l|}{ Umur } \\
\hline - Infant & 21 & 43,8 \\
\hline - Toddler & 9 & 18,7 \\
\hline - Preschool & 4 & 8,3 \\
\hline - School & 14 & 29,2 \\
\hline \multicolumn{3}{|l|}{ Jenis Kelamin } \\
\hline - Laki Laki & 32 & 66,7 \\
\hline - Perempuan & 16 & 33,3 \\
\hline Total & 48 & 100,0 \\
\hline
\end{tabular}

Hasil menunjukkan bahwa dari 7 lembar observasi tidak lengkap, menggunakan aplikasi smartphone hanya $2(28,6 \%)$ yang tdk lenggkap, dari 10 lembar observasi lengkap tidak tepat, menggunakan aplikasi smartphone hanya 4 (40\%) yang tdk lengkap, dari 31 lembar observasi lengkap tepat dengan smartphone 28 (90.3\%) lengkap tepat. Analisa lanjut dengan Kappa test didapat Pvalue $=0,709>$ alpha $5 \%$ (>alpha 5\%), maka tidak terdapat kesepakatan (kesamaan) yang signfikan antar lembar observasi dan aplikasi smartphone. Hal ini berarti terdapat perbedaan hasil lembar observasi dengan aplikasi smartphone monitoring keseimbangan cairan pada anak dengan penyakit infeksi. Aplikasi smartphone lebih effektif hal ini dibuktikan dari hasil 39 (81.3\%) lengkap dan tepat (Tabel 2). 
Tabel 2. Pengawasan Keseimbangan Cairan dengan Lembar Observasi dan Aplikasi Smartphone Di Ruang Rawat Anak Infeksi

\begin{tabular}{|c|c|c|c|c|c|c|c|c|}
\hline \multirow{3}{*}{ Lembar Observasi } & \multicolumn{6}{|c|}{ Aplikasi SmartPhone } & \multirow{3}{*}{ Pvalue } & \multirow{3}{*}{$\begin{array}{c}\text { Kapaa } \\
\text { Test }\end{array}$} \\
\hline & \multicolumn{2}{|c|}{ Tidak lengkap } & \multicolumn{2}{|c|}{$\begin{array}{c}\text { Lengkap } \\
\text { Tepat }\end{array}$} & \multicolumn{2}{|c|}{ Total } & & \\
\hline & $\mathrm{n}$ & $\%$ & $\mathrm{n}$ & $\%$ & $\mathrm{n}$ & $\%$ & & \\
\hline Tidak lengkap & 2 & 28,6 & 5 & 71,4 & 7 & 100 & \multirow{4}{*}{0,709} & \multirow{4}{*}{0,163} \\
\hline Lengkap tidak Tepat & 4 & 40 & 6 & 60 & 10 & 100 & & \\
\hline Lengkap tepat & 3 & 9.7 & 28 & 90.3 & 31 & 100 & & \\
\hline Jumlah & 9 & 18.8 & 39 & 81,3 & 48 & 100 & & \\
\hline
\end{tabular}

\section{Pembahasan}

Berdasarkan hasil wawancara terstruktur kepada beberapa perawat dan orang tua pasien setelah menggunakan aplikasi SIMBaCaAn menyampaikan bahwa aplikasi ini mudah digunakan dan sangat membantu dalam penghitungan balans cairan. Perawat tidak perlu menghitung karena dengan menekan fitur penghitungan balans akan otomatis keluar hasil penghitungan balans sesuai dengan tanggal yang diingin kan. Penelitian ini menunjukkan bahwa penggunaan aplikasi SIMBaCaAn memiliki beberapa kelebihan yakni mudah dalam pengisiian dan tepat dalam penghitungan. Hasil uji Kappa diperoleh Pvalue 0.163 > alpha 5\%, artinya tidak terdapat kesepakatan (kesamaan) yang signfikan antar lembar observasi dan aplikasi smartphone. Hal ini berarti terdapat perbedaan hasil lembar observasi dengan aplikasi smartphone monitoring keseimbangan cairan pada anak dengan penyakit infeksi. Aplikasi smartphone lebih effektif hal ini dibuktikan dari hasil 39 (81.3\%) lengkap dan tepat.

Pengawasan keseimbangan cairan merupakan salah satu aspek perawatan yang paling penting untuk pasien anak. Aplikasi pengawasan keseimbangan ini dikembangkan dengan harapan dapat memudahkan tugas perawat dan menjamin ketepatan penghitungan pengawasan keseimbangan cairan. Penelitian Jackson \& Cunningham yang dilakukan di ruang bedah dimana dihasilkan total keseimbangan cairan yang dihitung secara elektronik akurat dalam semua kasus. ${ }^{7}$ Hasil ujicoba efektivitas aplikasi SIMBaCaAn ini menunjukkan bahwa terjadi peningkatan yang signifikan pada ketepatan dan kelengkapan pengawasan status cairan pasien anak. Teknologi seluler dapat membantu 
manusia untuk mencatat intake dan memantaunya secara real time. ${ }^{9}$ Hasil studi menunjukkan bahwa menggunakan perangkat seluler untuk mencatat masukan dan keluaran pada orang yang terbiasa dengan teknologi ponsel menjadi sesuatu yang tepat. ${ }^{10}$

Anak yang dirawat seringkali mendapat terapi cairan ataupun obat melalui intravena atau oral serta lain termasuk makanan dan susu sehingga penghitungan cairan yang sangat akurat harus dilakukan untuk pengobatan yang tepat ${ }^{8}$. Penelitian Jackson dan Cunningham menyatakan bahwa pengawasan keseimbangan cairan dimasukkan secara tidak akurat pada lembar balans cairan karena kesalahan intake atau output. ${ }^{7} \mathrm{Hal}$ ini sejalan dengan penelitian Vincent dan Mahendiran menemukan bahwa ratarata tingkat penyelesaian chart lembar keseimbangan cairan manual hanya terisi $50 \% .{ }^{11}$

Perawat yang merawat pasien bertanggung jawab untuk memastikan bahwa bagan keseimbangan cairan dicatat secara teratur dan akurat dengan menggunakan pencatatan yang benar. Untuk memastikan hidrasi yang memadai, dan asuhan keperawatan yang aman dan efektif, perawat harus selalu melaporkan setiap kelainan signifikan yang diidentifikasi dalam catatan cairan pasien. ${ }^{12}$ Saat ini kemajuan teknologi smartphone dapat menjadi alat bantu yang mempermudah pekerjaan perawat dalam menghitung balans cairan.

Hasil survey Kaluza pada tahun 2017 menyatakan banyak perawat mengakui bahwa perawat sangat menyukai fitur elektronik yang ditawarkan untuk pengawasan keseimbangan cairan dibandingkan kertas. Tidak hanya akurasi total cairan, tetapi juga visibilitas dan aksesibilitas lebih cepat dibanding ke lembaran kertas. Bagan elektronik tidak akan salah seperti kertas dan tidak dapat hilang, yang terkadang menjadi masalah umum ketika catatan kertas hanya ada dalm satu dokumen yang dapat dengan mudah salah tempat. ${ }^{13}$

Penggunaan aplikasi cairan lebih dapat diterima daripada pencatatan secara manual dilihat dari segi manfaat, kemudahan, dan tampilan atau fitur aplikasi. Kelemahan kertas adalah kertas tidak selalu tersedia saat hendak menulis sedangkan smartphone selalu dipegang dan dibawa kemana mana sehingga mudah dalam pengaplikasian dan data langsung tersimpan, akan tetapi ada kendala yang timbul saat perjalanan penelitian ini yakni koneksi internet yang tidak stabil, seperti yang disampaikan oleh Rahmah et al., Tahun 2020, yang menyatakan koneksi internet dapat memengaruhi keterlibatan 
pengguna sebagai bagian dari masalah operasional umum dalam aplikasi. ${ }^{14}$

\section{Kesimpulan}

Penggunaan aplikasi teknologi merupakan inovasi yang diharapkan akan mempermudah dalam pekerjaan. Apliikasi SIMBaCaAn ini lebih efektif terhadap pencatatan keseimbangan cairan secara lengkap tepat dibandingkan dengan pengawasan keseimbangan cairan menggunakan lembar manual. Untuk memaksimalkan hasil dalam pelaksanaan penggunaan aplikasi ini memerlukan kerjasama sama yang baik antara pendamping pasien dan perawat agar pengawasan keseimbangan cairan ini dapat dilakukan dengan benar, perlu penguatan dalam penyediaan fasilitas yang memperkuat koneksi jaringan dan dapat dilakukan penggabungan dengan system informasi yang ada di rumah sakit sehingga memudahkan dalam akses data yang dihasilkan.

\section{Ucapan Terima Kasih}

Penulis mengucapkan terima kasih kepada Dosen Fakultas IImu keperawatan (FIK) Universitas Indonesia dan keluarga besar RSPI Sulianti Saroso yang telah memberikan dukungan dan bimbingan dalam pelaksanaan dan penulisan artikel ini

\section{Daftar Pustaka}

1. Agro FE. Body Fluid Management from Physiology to Therapy. Body Fluid Management. Italia: Springer; 2013.

2. Raina R, Sethi SK, Wadhwani N, Vemuganti M, Krishnappa V, Bansal SB. Fluid overload in critically ill children. Front Pediatr. 2018;6(October).

3. Gomes PP de S, Lima FET, Araújo PR, Oliveira MR de, Brito EGFM de, Carneiro JL, et al. Water balance in pediatric nephrology: construction of a Standard Operating Procedure. Rev Bras Enferm. 2018;71(CVI):1404-11.

4. Langer T, Santini A, Scotti E, Van Regenmortel N, Malbrain MLNG, Caironi P. Intravenous balanced solutions: From physiology to clinical evidence. Anaesthesiol Intensive Ther. 2015;47(1):s78-88.

5. Terris $M$, Crean P. Fluid and electrolyte balance in children. Anaesth Intensive Care Med [Internet]. 2017;18(11):567-71. Available from: https://doi.org/10.1016/j.mpaic.201 7.07.009

6. Jeyapala S, Gerth A, Patel A, Syed $N$. Improving fluid balance monitoring on the wards. BMJ Qual Improv. 2015;5-7. 
7. Jackson $\mathrm{C}$, Cunningham $\mathrm{C}$. Electronic fluid balance chart recording: An audit of accuracy for clinical decision-making on a surgical ward. Int J Surg [Internet]. 2017;47:S60. Available from: https://doi.org/10.1016/j.ijsu.2017.0 8.310

8. Thinnukool $\mathrm{O}$, Khuwuthyakorn $\mathrm{P}$, Sukwuttichai P. Pediatric fluid therapy calculator mobile application (PFTC). ACM Int Conf Proceeding Ser. 2017; Part F1312:83-7.

9. Lee JE, Song S, Ahn JS, Kim Y, Lee JE. Use of a mobile application for self-monitoring dietary intake: Feasibility test and an intervention study. Nutrients. 2017;9(7).

10. Porter J, Huggins CE, Truby $\mathrm{H}$, Collins J. The effect of using mobile technology-based methods that record food or nutrient intake on diabetes control and nutrition outcomes: A systematic review. Nutrients. 2016;8(12).

11. Vincent $M$, Mahendiran $T$. Improvement of fluid balance monitoring through education and rationalisation. BMJ Qual Improv Reports.

2015;4(1):u209885.w4087.

12. Shepherd A. Measuring and managing fluid balance. Nurs time. 2011;107(28).
13. Kaluza BV. Fluid balance the electronic journey. In: Nervecentre. 2017. p. 1-6.

14. Rahmah HA, Wahyurin IS, Khoiriani IN, Hapsari PW. Smartphone-based application vs paper-based record: Female adolescents acceptance on fluid record tool. Malays J Nutr. 2020;26(3):487-94. 